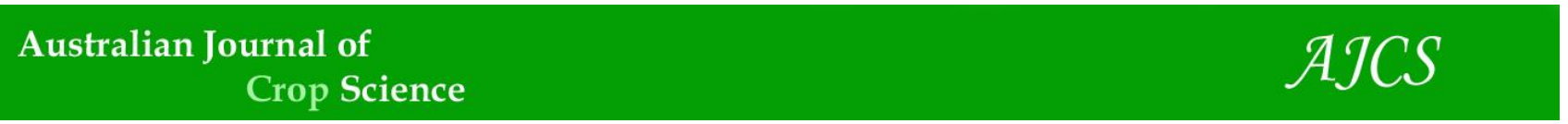

AJCS 15(03):325-333 (2021)

ISSN:1835-2707

doi: 10.21475/ajcs.21.15.03.p2503

\title{
Thermal degradation kinetics and physicochemical analysis of the freeze-dried hibiscus flower extract (Hibiscus sabdariffa)
}

\author{
Auryclennedy Calou de Araújo ${ }^{1 *}$, Francislaine Suelia dos Santos ${ }^{1}$, Marylia de Sousa Costa', Karoline Thays \\ Andrade de Araújo', Josivanda Palmeira Gomes', Wilton Pereira da Silva', Alexandre José de Melo \\ Queiroz', Geovani Soares de Lima', Lauriane Almeida dos Anjos Soares', Ângela Maria Santiago²
}

\author{
${ }^{1}$ Federal University of Campina Grande, Academic Unit of Agricultural Engineering, Campina Grande, 58.109-970, \\ Paraíba, Brazil \\ ${ }^{2}$ Estate University of Paraíba, Department of Industrial Chemistry, Campina Grande, 58101-001, Brazil
}

*Corresponding author: auryclennedy@hotmail.com

\begin{abstract}
The goal of this research was to evaluate the kinetics of thermal degradation of the hibiscus extracts powder at different temperatures and to characterize physicochemically the freeze-dried aqueous extract of the hibiscus flower (Hibiscus sabdariffa) with different concentrations of maltodextrin $(0,5,10$ and 15\%). The analyzed parameters were: water content, total soluble solids, titratable acidity, $\mathrm{pH}$, ash, solubility, hygroscopicity, bulk and tapped density, the flowability (Carr index) and cohesiveness (Hausner ratio), lightness $\left(\mathrm{L}^{*}\right)$ and intensity of red $\left(\mathrm{a}^{*}\right)$ and yellow $\left(\mathrm{b}^{*}\right)$. The degradation kinetics was analyzed by the determination of bioactive compounds of flavonoids, anthocyanins and color appearance parameters (lightness, intensity of red and yellow, chroma and hue angle). The increase in maltodextrin concentration resulted in increases of solubility, soluble solids content, $\mathrm{pH}$ and color appearance parameters; as the parameters of bulk and tapped density, hygroscopicity, water content, ash and acidity presented decreases as the proportion of additive increased, showing good flowability and low to medium cohesion. Regarding the degradation kinetics, the maltodextrin was effective in the preservation of anthocyanins and flavonoids of the freeze-dried hibiscus flower up to the temperature of $50^{\circ} \mathrm{C}$. Therefore, this work resulted in the preparation of a product derived from the freeze-drying process with and without additives and with preserved sensory attributes of high quality.
\end{abstract}

Keywords: Hibiscus sabdariffa L.; anthocyanins; bioactives; degradation kinetics; aqueous extract; flavonoids.

Abbreviations: $\mathrm{pH}$ _hydrogen potential; DE_dextrose equivalent; DW_dry water; p/p_powder Pulp; ${ }^{\circ} \mathrm{Bx} \_$_-Brix; HR_Hausner ratio; SSC_soluble solids content; $\mathrm{Cl} \_$Carr index; $\mathrm{NaCl} \_$sodium chloride; $\rho$ ap_bulk density; $\rho$ c_tapped density.

Introduction

The hibiscus is a species of the genus Hibiscus in the Malvaceae family and it is a plant of Indian origins, more accurately from Sudan and Malaysia (Maciel et al., 2012). In different regions of Brazil this plant is also known as hibiscus, rosela, groselha, azedinha, quiabo azedo, among others. It is known that this species is a great source of antioxidant and its actions are significant in the treatment of hypertension, gastrointestinal disorder, liver diseases, as well as reducing lipid and cholesterol levels (Silva, 2011).

The search for a healthier life caused an increase in the demand for hibiscus as a consequence of the studies and researches showing its great potential when it comes to health benefits. Due to the hibiscus functionality, great interest emerged from industries to use this species as a food component for the preparation of several products in the food industry such as teas, fermented beverages, soft drinks, jellies, ice cream, chocolates and cakes (Costa et al., 2014).

There are several drying methods that can be applied to fruits and vegetables, such as tray drying, sun drying, foam mat drying, spray drying and freeze-drying/ lyophilization. The freeze-drying is a drying method that occurs under special conditions of low temperature and pressure, allowing the water in the solid phase (frozen) to go directly to the gaseous phase through the sublimation process. By using low temperatures, freeze-drying preserves better the heatsensitive components of food; however when compared to other types of drying it is a relatively expensive process, despite achieving good results.

Zotarelli et al. (2012) report that because the water is removed from a frozen product in the freeze-drying process, a porous structure is formed resulting in a dehydrated product with better proprieties when rehydrated. Although the hygroscopic nature of freeze-dried products be an advantage for rehydration, the adsorption of water vapor during storage and distribution can become a serious problem (Rhim et al., 2011). For this reason Galmarini et al. (2011) suggest that to improve the quality of freeze-dried materials one should consider the use of freeze-drying additives, such as maltodextrin with different dextrose equivalent (DE) and gum arabic. In addition to allow the achievement of less hygroscopic powders, these additives can produce 'loose' powders of easy handling and good quality (Mosquera et al., 2012). 
Given the information above, the goals of this research were to perform the chemical, physical and physicochemical characterization of the freeze-dried aqueous extract of the hibiscus flower with different concentrations of maltodextrin and to evaluate the kinetics of thermal degradation of the studied extracts powder at different temperatures.

\section{Results and discussion}

\section{Chemical and physicochemical characterization of hibiscus} extracts powder

The Table 1 presents the mean values and standard deviation of the chemical and physicochemical characterizations of the freeze-dried hibiscus extracts powder with and without addition of maltodextrin. It was observed that the water content of the powder without addition of maltodextrin corresponded to $13.46 \%$, value close to the ones found in the studies of Silva et al. (2016) when analyzing the chemical compounds of the Chinese hibiscus flowers; it also presented a water content of $13.91 \%$ D.W., and in the studies of Sobota et al. (2016), the evaluation of the physicochemical profile of the calyx of the species Hibiscus sabdariffa L. determined water content of $12.90 \%$. With the increase of maltodextrin concentration in the hibiscus powder the water content was reduced from $13.46 \%$ to $7.93 \%$ when the maltodextrin concentration increased from 0 to $15 \%$, respectively. This same behavior was observed by Oliveira et al. (2014) when they evaluated the characterization of the Spondias mombin pulp powder with and without addition of maltodextrin and they observed that its water content decreased from 2.05 to $0.65 \%$ after the addition of $17 \%(\mathrm{p} / \mathrm{p})$ of maltodextrin; concluding that this decrease can be attributed to the higher amount of solids present in this pulp. The determination of total ash content refers to the remaining inorganic residue after the complete destruction of the food organic matrix. The values found for the hibiscus powders varied from $9.34 \%$ for the powder without addition and from 8.60 to $6.96 \%$ for the powders with different concentrations of maltodextrin; no significant difference was verified for the concentration of 10 and $15 \%$. Sobota et al. (2016) evaluated the physicochemical profile of the calyx of the species Hibiscus sabdariffa $\mathrm{L}$. and found ash content of $9.27 \%$.

The effect of adding up to $15 \%$ of maltodextrin to the hibiscus extract caused a great decrease in its titratable acidity, while the amount of total solids ( $\left.{ }^{\circ} \mathrm{Bx}\right)$ increased significantly with the increase of the maltodextrin concentration; therefore Oliveira et al. (2014) confirmed that this fact explains the decrease in acid content of the powder containing higher percentage of maltodextrin. Studies by Oliveira et al. (2017) regarding the freeze-drying of the "Rosa" mango pulp with and without addition of maltodextrin indicate that the addition of additives also reduced the titratable acidity and increased the $\mathrm{pH}$ of their samples. The $\mathrm{pH}$ of the hibiscus powder with the addition of different concentrations of maltodextrin did not present significant differences between each other, since these values are higher in comparison to the $\mathrm{pH}$ value of the powder sample without the addition of maltodextrin. The slightly acid $\mathrm{pH}$ is due to the water solubility of pigments, such as anthocyanins, which are present in the hibiscus leaves (Hayashi, 1962; Timberlake et al., 1975).

The color appearance parameters of the powders, such as lightness and intensity of red and yellow, increased as the concentrations of maltodextrin also increased. The lightness presented results similar to those found by Tonon et al. (2009) in their work with açai powder added with different concentrations of maltodextrin; they realized that with the increase of concentrations of this additive the lightness also increased, unlike the intensity of red $a^{*}$ which decreased and the intensity of yellow $b^{*}$ which did not present significant difference with the increase of the maltodextrin concentrations. However, in this research the values of a* for all the powders with and without the addition of maltodextrin presented positive values, indicating that these powders present more reddish tones, although it was also possible to observe that the red intensity increased with the increase of the additive concentration, which can be justified by the action of this agent in the conservation of pigments (anthocyanins and flavonoids) (Silva, 2007).

Regarding the intensity of yellow $b^{*}$, the results were also positive tending towards more yellowish pigments and these attributes were also increasing as the concentrations of maltodextrin increased. These results were opposite to the ones found by Oliveira et al. (2014) in their work with freezedried Spondias mombin pulp added with maltodextrin, in which the powders containing maltodextrin presented increase in lightness and decrease in red and yellow intensity.

\section{Physical characterization of hibiscus extracts powder}

The Table 2 presents the mean values and standard deviation of the physical characterizations of the freezedried hibiscus extract powder with and without addition of maltodextrin. It can be observed that there was a significant increase in the solubility values with the increase of maltodextrin in the samples; according to Sogi et al. (2015) this behavior is related not just to the presence of sugars, but mostly to the addition of highly water-soluble adjuvants. Solubility is an important propriety of edible raw materials because poorly soluble powders can cause processing difficulties which can result in economic losses in the industry, as reported by Sharma et al. (2012) in their studies on the functionality of milk powders. Lower values were reported for the powder of hibiscus leaves (Hibiscus sabdariffa L.) obtained by foam mat drying at temperatures of 60 to $80^{\circ} \mathrm{C}$, presenting solubility between 30.4 and $50.5 \%$ (Cavalcante Neto, 2017).

The powders presented high hygroscopicity, particularly the powder without additive addition and the one with 5\%; the fact that this parameter reduced with the biggest increase of the maltodextrin proportion confirms the efficiency of the use of drying adjuvants to reduce the hygroscopicity of dehydrated products (Tonon et al., 2009). Similar behavior was observed by Costa et al. (2014) when studying the physical characteristics of the soursop pulp powder obtained by spray drying, in which the authors used 15,30 and $45 \%$ of maltodextrin, determining that the use of this additive was efficient to reduce the hygroscopicity of the produced soursop powders, with reduction around $45 \%$ due to the high concentrations used.

The bulk density significantly reduced with the increase of maltodextrin concentration, indicating that for the same mass of hibiscus extract powder, the higher the level of additives, the bulkier the product becomes. This observation is important, especially for packaging and/or storage of powder products, since it can be used to better sizing of packages and/or warehouses. It was also observed a direct correlation of bulk density to solubility, suggesting that the 
more voluminous the powder (that is, the less dense) the greater is its solubility (Sogi et al., 2015).

Regarding the tapped density, Medeiros and Lannes (2010) affirm that it is understood as the compression of a biphasic system, solid and gas (powder and air), under the action of a force which results in the reduction of the product volume. To determine the compaction is useful to evaluate the flow, verify the tendency to friction and the agglomeration of powders. It was verified similar behavior between tapped and bulk density, with significant statistical decrease with the increase of maltodextrin proportion. Close values were observed for the tomato pulp dehydrated by convective drying at the temperatures of 60 and $80{ }^{\circ} \mathrm{C}$, in which the powders without albumin presented tapped density values of 0.267 and $0.454 \mathrm{~g} / \mathrm{cm}^{3}$ respectively (Fernandes et al., 2014).

The Carr index $(\mathrm{Cl})$ or compressibility index of the extract powders of the freeze-dried hibiscus presented means from 16.67 to $20.00 \%$. There was increase of the index with the increase of maltodextrin proportion. This index measures the powders capacity of flow. Values of $\mathrm{Cl}$ between $15-20 \%$ have good flowability, between 20-35 poor flowability, between $35-45 \%$ very poor flowability and $\mathrm{Cl}>45$ extremely poor flowability (SanthalakshmY et al., 2015). Therefore, it was verified that all the powders in this study presented good flowability regardless of any additive addition. Caliskan and Dirim (2016), when drying sumac (Rhus coriaria) with $20 \%$ of maltodextrin in different drying processes, spray drying and freeze-drying, verified flowability of 33.94 and $25.02 \%$, respectively, with the greater values for the freezedried material.

The mean values of Hausner ratio (HR) varied from 1.20 to 1.25, parameter which evaluates the cohesiveness of powder products, observing that the increases of maltodextrin in the powders resulted in a significant increase of HR. According to Santhalakshmy et al. (2015), powders which presented Hausner ratio inferior to 1.2 are classified as low cohesion, HR from 1.2 to 1.4 are medium cohesion and HR > 1.4 are considered of high cohesion. Therefore, the studied powders presented low to medium cohesion. Yusof et al. (2012) reported HF of 1.24 in the pitaya pulp powder obtained by spray drying, values similar to the ones of this study.

\section{Thermal degradation of hibiscus extracts powder}

In the Fig 1 are expressed the results of the flavonoid values present in the freeze-dried hibiscus extract with different concentrations of maltodextrin $(0,5,10$ and 15\%) and their behavior when subjected to high temperatures $(40,50,60$ and $70 \mathrm{o} C)$. The formulations with higher maltodextrin concentrations presented the highest initial values related to the content of flavonoids present in the sample, a total found of 37.08 and $36.80 \mathrm{mg} .100 \mathrm{~g}^{-1}$ for the formulations with 10 and $15 \%$ of maltodextrin, respectively, which did not differ statistically from each other. The formula with the lowest content of flavonoids was the standard sample, without addition of drying additive in its formulation,

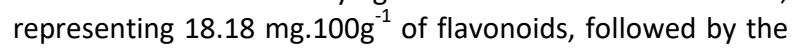
sample with $5 \%$ of maltodextrin with value of 33.27 $\mathrm{mg} .100 \mathrm{~g}^{-1}$; such behavior is due to the fact that the drying additive used worked as a protective agent for these compounds during the freeze-drying, in which it was observed that as the concentration of maltodextrin increased, greater was the preservation of flavonoids during drying, with this effect being stabilized in the formulation with $10 \%$, since no statistical difference was found when comparing to the formulation with the highest concentration of $15 \%$. It was noted that there was a degradation in the total amount of flavonoids throughout the experiment, as the samples were subjected to high temperatures $(40,50,60$ e $70{ }^{\circ} \mathrm{C}$ ) simulating a baking process, the compounds were degraded. According to a review by Arancibia-Avila et al. (2012), most mentioned researchers concluded that the thermal processing of fruits and vegetables significantly reduces the content of their bioactive compounds and the level of antioxidant activity, as occurred in our study with the variable flavonoids.

The formulation that best preserved the analyzed bioactive compounds was the sample with $10 \%$ of maltodextrin, presenting a total loss of $3.29 \%$ of flavonoids at the end of the experiment when the temperature reached $70 \circ \mathrm{C}$, followed by the formulation with $15 \%$ of maltodextrin which had a reduction of $13.42 \%$ in the total flavonoids; the sample with lower maltodextrin concentration of $5 \%$, presented a decrease of $19.53 \%$ of flavonoids, and the sample with the lowest flavonoid preservation power when subjected to high temperatures was the standard sample without addition of maltodextrin in its composition, with a decrease of $23 \%$ of flavonoids after the thermal degradation.

In the Fig 2 are expressed the results of the anthocyanin values present in the freeze-dried hibiscus extract with different concentrations of maltodextrin $(0,5,10$ and $15 \%)$ and their behavior when subjected to high temperatures $(40,50,60$ e $70 \stackrel{\circ}{ } \mathrm{C})$. It was verified that the percentage of maltodextrin influenced in the preservation of anthocyanins, a fact similar to what happened when the flavonoids were analyzed. In the initial values, the influence of the percentage of the drying additive is observed in the preservation of these pigments during freeze-drying; all the formulations differed statistically when compared to each other, with the formulation of $10 \%$ being the one that presented the best results in this first moment representing $57.24 \mathrm{mg} .100^{-1}$ of anthocyanins followed by the formulation of $15 \%$, with values of $56.63 \mathrm{mg} .100^{-1}$ and the formulations with lower values of 5 and $0 \%$ of maltodextrin, that obtained averages of 49.91 and $39.79 \mathrm{mg}^{-100^{-1}}$ respectively. The values of anthocyanins decreased when the samples were submitted to high temperatures $\left(40,50,60\right.$ and $\left.70{ }^{\circ} \mathrm{C}\right)$; this pattern can be explained due to the degradation of anthocyanins during the experiment and the formation of new pigments. In their work with blackberries harvested in three different points of harvest, Souza et al., (2018) also verified this behavior regarding the anthocyanin, which can be explained in the present experiment, since these pigments presented sensibility to heating temperatures.

It is observed that when reaching the temperature of $60^{\circ} \mathrm{C}$, the values of anthocyanins presented a quite stronger decrease compared to previous heating points; this behavior is observed in the formulations with maltodextrin in their composition, while the standard sample, with no addition of maltodextrin, kept its gradual decreasing behavior. The maltodextrin behaved as a protective barrier for these pigments up to the temperature of $50{ }^{\circ} \mathrm{C}$, in which the losses of anthocyanins represented $16.00,11.09$ and $10.63 \%$ for the formulations with 5, 10 and $15 \%$ of maltodextrin, respectively. The highest point of degradation of anthocyanins, in which one can observe the highest loss between two temperatures, occurred when the samples were subjected to the temperature of $60^{\circ} \mathrm{C}$. 
Table 1. Mean values and standard deviation of the chemical and physicochemical characteristics of the freeze-dried hibiscus extract powder with and without addition of maltodextrin.

\begin{tabular}{|c|c|c|c|c|}
\hline \multirow[b]{2}{*}{ Parameters } & \multicolumn{4}{|c|}{ Concentration of maltodextrin } \\
\hline & $0 \%$ & $5 \%$ & $10 \%$ & $15 \%$ \\
\hline Water content (\%) & $13.46 \pm 1.34 \mathrm{a}$ & $8.78 \pm 0.13 b$ & $8.72 \pm 0.16 b$ & $7.93 \pm 0.10 b$ \\
\hline Ash (\%) & $9.34 \pm 0.74 \mathrm{a}$ & $8.60 \pm 0.08 b$ & $7.58 \pm 0.01 \mathrm{c}$ & $6.96 \pm 0.12 c$ \\
\hline $\begin{array}{l}\text { Total titratable acidity } \\
\text { (g of citric acid/100g) }\end{array}$ & $24.12 \pm 0.98 \mathrm{a}$ & $19.31 \pm 0.28 b$ & $16.23 \pm 0.46 \mathrm{c}$ & $13.55 \pm 0.17 d$ \\
\hline Total soluble solids ( ${ }^{\circ} \mathrm{Brix}$ ) & $8.50 \pm 0.00 \mathrm{c}$ & $8.73 \pm 0.12 b$ & $8.87 \pm 0.12 a b$ & $9.00 \pm 0.00 \mathrm{a}$ \\
\hline $\mathrm{pH}$ & $2.67 \pm 0.05 b$ & $2.83 \pm 0.02 \mathrm{a}$ & $2.84 \pm 0.02 \mathrm{a}$ & $2.86 \pm 0.02 \mathrm{a}$ \\
\hline Lightness ( $\left.\mathrm{L}^{*}\right)$ & $3.65 \pm 0.02 \mathrm{~d}$ & $3.96 \pm 0.05 c$ & $4.87 \pm 0.10 \mathrm{~b}$ & $5.31 \pm 0.08 \mathrm{a}$ \\
\hline Intensity of red (+a*) & $20.12 \pm 0.16 c$ & $22.71 \pm 0.60 \mathrm{~b}$ & $23.68 \pm 0.46 b$ & $26.95 \pm 0.61 \mathrm{a}$ \\
\hline Intensity of yellow ( $\left.+b^{*}\right)$ & $2.90 \pm 0.74 \mathrm{c}$ & $3.99 \pm 0.32 b c$ & $4.58 \pm 0.25 \mathrm{ab}$ & $5.46 \pm 0.65$ a \\
\hline
\end{tabular}

Means followed by the same letter in the lines do not differ statistically by the Tukey test at $5 \%$ probability.

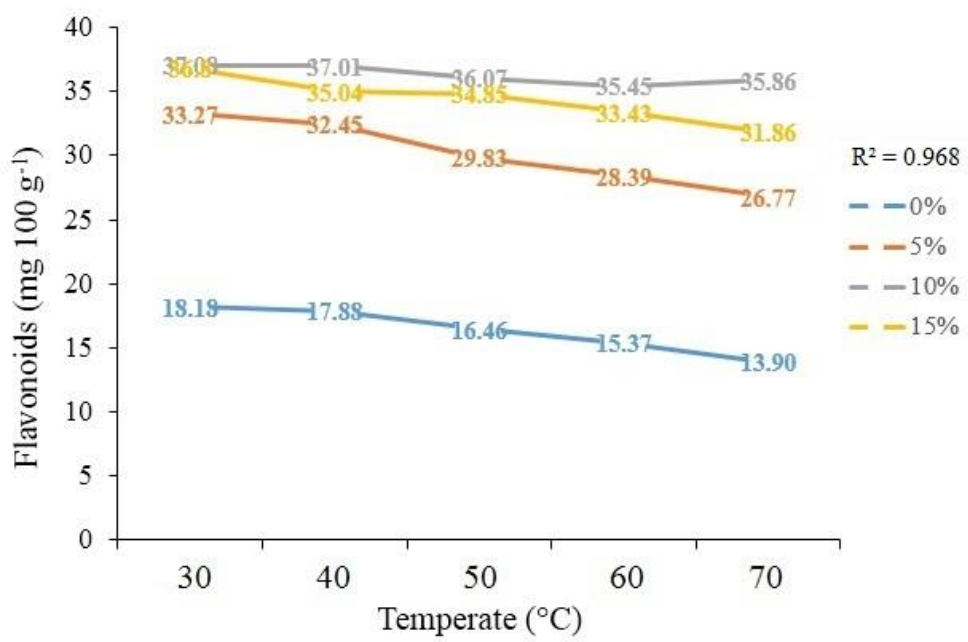

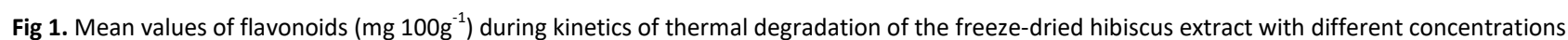
of maltodextrin.

Table 2. Mean values and standard deviation of the physical characteristics of the freeze-dried hibiscus extract powder with and without addition of maltodextrin.

\begin{tabular}{llll}
\hline \multirow{2}{*}{ Parameters } & \multicolumn{3}{c}{ Concentration of maltodextrin } \\
\cline { 2 - 4 } & $0 \%$ & $5 \%$ & $10 \%$ \\
\hline Solubility (\%) & $52.98 \pm 0.74 \mathrm{~d}$ & $61.01 \pm 1.09 \mathrm{c}$ & $69.80 \pm 2.90 \mathrm{~b}$ \\
Hygroscopicity (\%) & $85.42 \pm 0.03 \mathrm{a}$ & $80.81 \pm 0.01 \mathrm{~b}$ & $76.48 \pm 0.06 \mathrm{c}$ \\
Bulk density $\left(\mathrm{g} . \mathrm{cm}^{-3}\right)$ & $0.420 \pm 0.012 \mathrm{~b}$ & $0.398 \pm 0.008 \mathrm{ab}$ & $0.388 \pm 0.011 \mathrm{~b}$ \\
Tapped density $\left(\mathrm{g} . \mathrm{cm}^{-3}\right)$ & $0.504 \pm 0.015 \mathrm{a}$ & $0.495 \pm 0.09 \mathrm{a}$ & $0.485 \pm 0.008 \mathrm{a}$ \\
Carr index (\%) & $16.67 \pm 1.15 \mathrm{~b}$ & $18.67 \pm 0.58 \mathrm{ab}$ & $0.449 \pm 0.74 \mathrm{a}$ \\
Hausner ratio & $1.20 \pm 0.02 \mathrm{~b}$ & $1.23 \pm 0.01 \mathrm{ab}$ & $19.33 \pm 1.15 \mathrm{a}$ \\
\hline
\end{tabular}

Means followed by the same letter in the lines do not differ statistically by the Tukey test at 5\% probability.

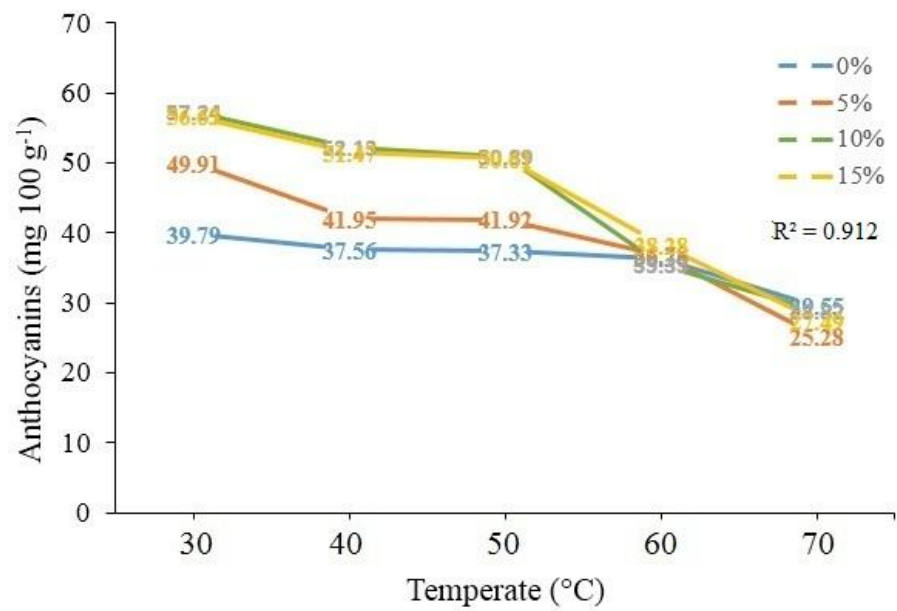

Fig 2. Mean values of anthocyanins $\left(\mathrm{mg} \cdot 100 \mathrm{~g}^{-1}\right)$ during kinetics of thermal degradation of the freeze-dried hibiscus extract with different concentrations of maltodextrin. 


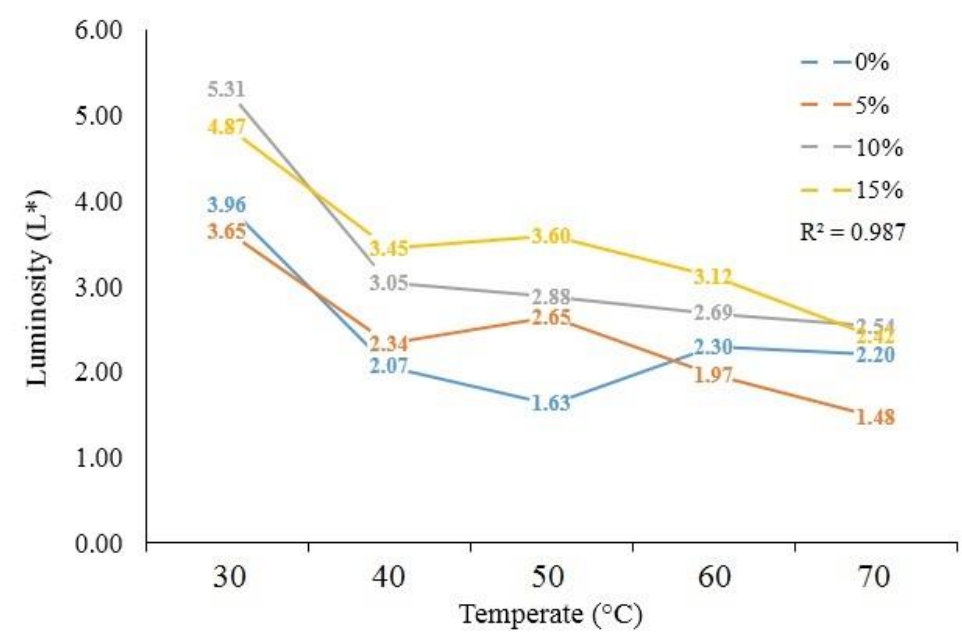

Fig 3. Mean values of lightness $\left(L^{*}\right)$ during kinetics of thermal degradation of the freeze-dried hibiscus extract with different concentrations of maltodextrin.

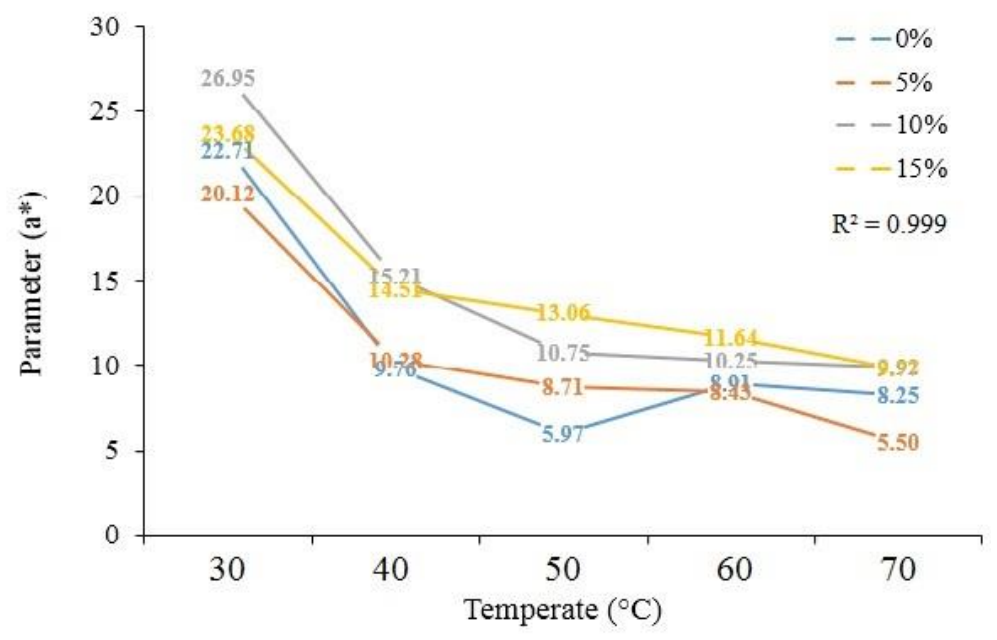

Fig 4. Mean values of parameter a* during kinetics of thermal degradation of the freeze-dried hibiscus extract of with different concentrations of maltodextrin.

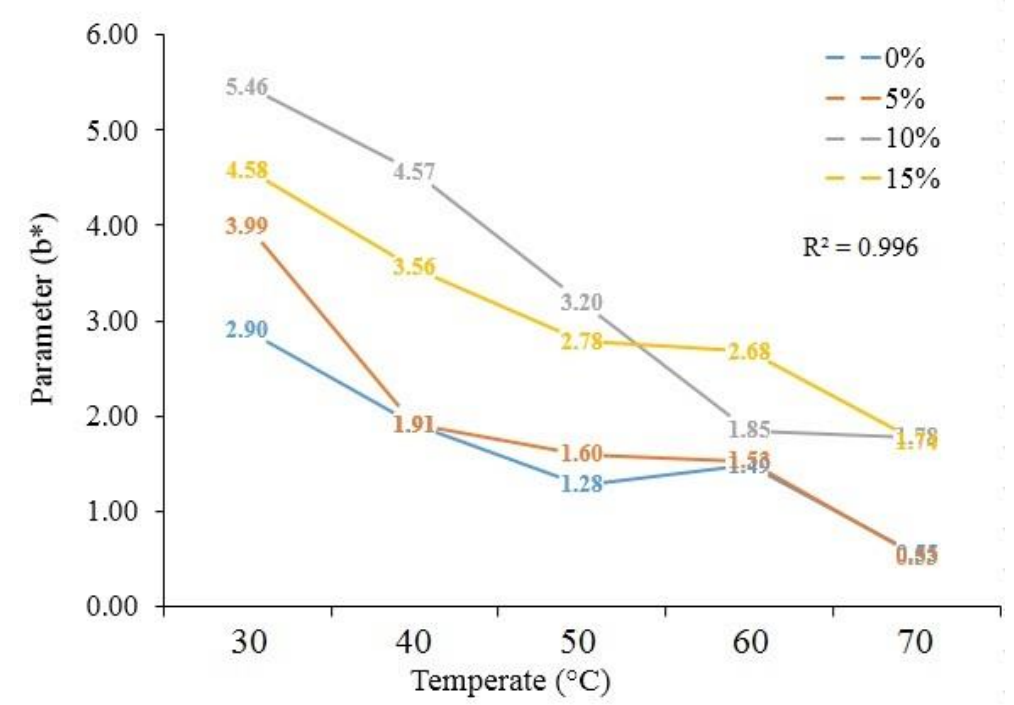

Fig 5. Mean values of parameter $b^{*}$ during kinetics of thermal degradation of the freeze-dried hibiscus extract with different concentrations of maltodextrin. 


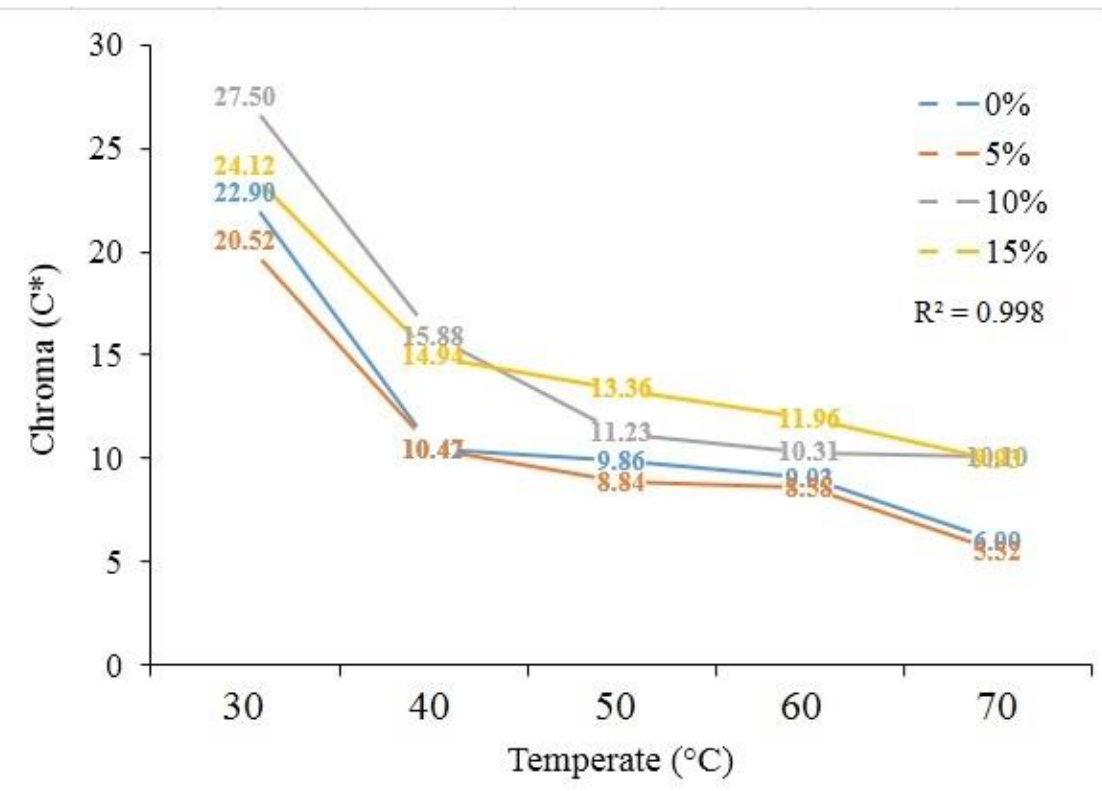

Fig 6. Mean values of chroma $C^{*}$ during kinetics of thermal degradation of the freeze-dried hibiscus extract with different concentrations of maltodextrin.

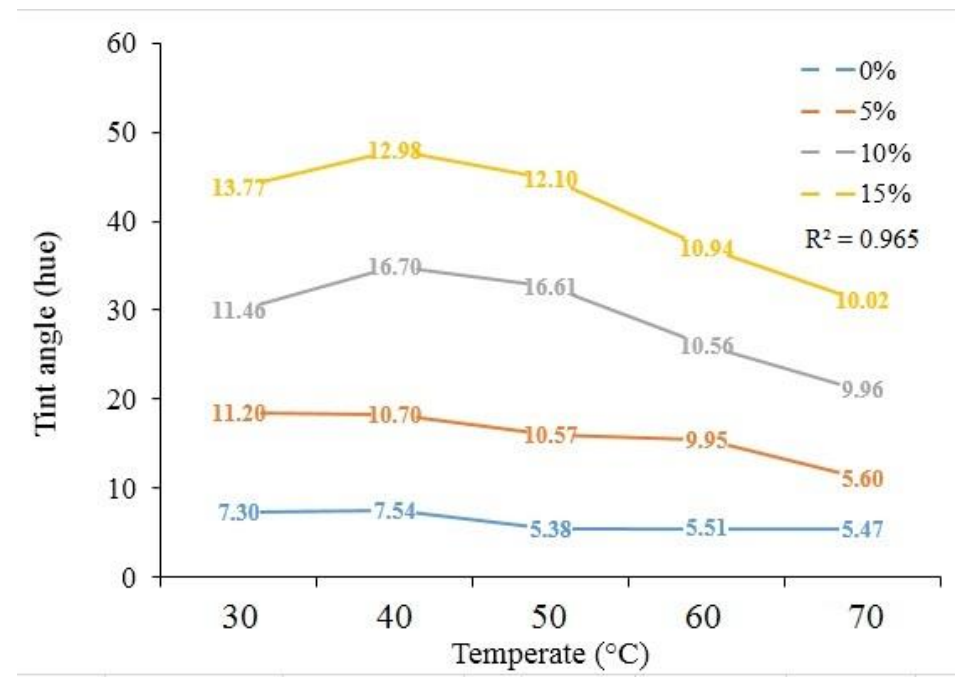

Fig 7. Mean values of tint angle (hue) during kinetics of thermal degradation of the freeze-dried hibiscus extract with different concentrations of maltodextrin.

At the end of the experiment, when the samples reached the temperature of $70{ }^{\circ} \mathrm{C}$, the standard sample without maltodextrin had a decrease of $25.73 \%$ in its content of anthocyanins, followed by 49.34 and $49.65 \%$ of loss of anthocyanins in the samples with 5 and $10 \%$ of maltodextrin, respectively. The sample which presented the highest percentage of anthocyanin loss, at the experiment's end, was the formula with $15 \%$ of maltodextrin in its composition, presenting a percentage of $51.45 \%$ of degradation of anthocyanins, thus concluding that the samples with maltodextrin in its formula were not effective in preserving this pigment when subjected to temperatures above $50^{\circ} \mathrm{C}$.

Behavior similar to the one of this study was observed by Silva et al. (2016), when they quantified the anthocyanins present in industrialized acerola pulp; the pulps were submitted to thermal degradation and presented a reduction of $17.04 \%$ in their pigments when exposed to the temperature of $60{ }^{\circ} \mathrm{C}$, while the degradation carried at a temperature of $70{ }^{\circ} \mathrm{C}$ presented reduction of $40.37 \%$ of total anthocyanins.

The color appearance parameters of the freeze-dried hibiscus extract with different concentrations of maltodextrin are shown in Figures 3, 4, 5, 6 and 7. The data obtained in thermal degradation at the five studied temperatures were analyzed in terms of order of reaction; the graphs were plotted with the values collected in the analysis performance versus the heating temperature.

The Fig 3 shows the lightness of the powders during thermal degradation. Initially it is verified that the powder added with $10 \%$ of maltodextrin was the one that presented the highest lightness followed by the sample with $15 \%$ of this additive, but these values can be justified, since the hibiscus extract has dark color and the addition of maltodextrin, that has white color, caused higher lightness. During heating there was a significant reduction of lightness in all samples, with average reduction of $50 \%$ in relation to the initial values in the samples with 5, 10 and $15 \%$ of maltodextrin and $44 \%$ 
reduction for the sample without the additive $(0 \%)$. These alterations reflect the degradation of the natural pigments from the food matrix, that is, the anthocyanins and flavonoids present in the extract. This behavior was also observed in researches with heat treatments, like samples of fruit puree (Brito et al. 2011) and non-alcoholic drinks of hibiscus leaves (Martins et al. 2018).

The Fig 4 shows the values of the parameter $a^{*}$ that corresponds to the intensity of red of freeze-dried hibiscus extract with different concentrations of maltodextrin through the thermal degradation kinetics. The powders that presented higher amount of maltodextrin stood out in relation to the initial values, with the extract without additive transitioning from the purple/lilac color to a more intense red color. During degradation, the parameter $a^{*}$ presented the significant reduction of $58 \%$ in relation to the initial mean values in all the studied samples. This reaction is associated to the darkening of the sample already observed in lightness (Figure 3) and it can be linked to three important causes: caramelization of sugars in the sample, Maillard reaction and oxidation of vitamins during the process (Manzocco et al., 2000).

The Fig 5 shows the values of $b^{*}$ that represent the intensity of yellow of the freeze-dried hibiscus extract with different concentrations of maltodextrin during its thermal degradation kinetics. It was observed that the powders with higher percentages of additives were those with the highest intensity of yellow; and during the kinetics, as well as the parameters studied above, there was a significant decrease of color intensity with an average reduction in relation to the initial values above $80 \%$ in the powders with 0 and $5 \%$ of maltodextrin concentration and $62-67 \%$ in the powders with 10 and $15 \%$ of additive, respectively. It was verified that with the heating of the samples the color of the extracts powder approached negative values, that match the transition of yellow $\left(+b^{*}\right)$ to blue $\left(-b^{*}\right)$, corresponding to the alkaline condition of the anthocyanin present in the extract.

The chroma of hibiscus extract powder with different concentrations of maltodextrin during thermal degradation is presented in Fig 6, in which were verified higher means for the powders with higher concentration of the additive (10 and $15 \%$ ) in relation to the initial values. During degradation there was a significant reduction of the chroma values, mostly in the concentrations of 0 and $5 \%$, with decrease above $70 \%$ in relation to initial values. According to Canuto et al. (2010) the lowest values of chroma (close to zero) indicate higher opacity of samples, with neutral colors (grays), and the highest values (above 60) correspond to more intense, "vivid" shades. Therefore, the powders presented less intense colors and over the course of degradation they tended to neutral tones.

In the Fig 7 are the mean values of the hue angle of the freeze-dried hibiscus extract with different concentrations of maltodextrin during its thermal degradation kinetics. It was observed by the initial values that the increase in the additive proportion caused an intensification of hue in the powders and all of them remained with hues in the red zone, which corresponds to values close to the angle $h=0^{\circ}$ (Alves et al., 2008). During thermal degradation, there was a significant decrease in the hue of all the studied powder extracts, with reduction means above $20 \%$ in relation to the initial values.

\section{Materials and methods}

\section{Obtaining the raw material and extract}

The raw material used was the hibiscus (Hibiscus sabdariffa) flowers naturally dehydrated, exposed to the sun and commercialized in the local market of Campina Grande, PB, Brazil. The flowers were selected manually in order to eliminate dirt or unwanted materials. The aqueous extract was obtained from chopped hibiscus flowers in the ratio of $1: 3(\mathrm{~m} / \mathrm{v})$, in which to one portion of raw material were added three portions of distilled water.

The material was macerated and maintained for $24 \mathrm{~h}$ at room temperature $\pm 25^{\circ} \mathrm{C}$ in a glass container with lid and covered by aluminum foil, being homogenized by manual and slow shaking every $6 \mathrm{~h}$. After this period, the material was filtered in stainless steel sieve and formulated, resulting in 4 samples: pure extract $(0 \%)$ and the extracts added of 5 , 10 and $15 \%$ of maltodextrin. The formulated samples were subjected to freeze-drying. After drying the samples were macerated and stored in flexible laminated packaging, suitable for food, and hermetically sealed until further analyses.

\section{Chemical and physicochemical characteristics of the powders}

The following analyses were determined according to the analytical standards of the Institute Adolfo Lutz (2008). The water content was determined in an oven at $105{ }^{\circ} \mathrm{C}$ until constant mass; the soluble solids content (SSC) in an Abbe refractometer; total titratable acidity by the titrimetric method, titrating the samples with $0.1 \mathrm{M}$ sodium hydroxide solution using phenolphtalein as indicator; $\mathrm{pH}$ by direct reading in TEC-2 Tecnal $\mathrm{pH}$ meter, calibrating with buffer solutions of $\mathrm{pH} 4.0$ and 7.0; ash by incineration in muffle furnace at $550{ }^{\circ} \mathrm{C}$ and the color appearance parameters were determined by direct reading using the portable spectrophotometer Hunter Lab MiniScan XE Plus in the CIELAB color characterization system, determining the parameters: $L^{*}$ - lightness; $a^{*}$ - transition from green $\left(-a^{*}\right)$ to red $\left(+a^{*}\right)$; and $b^{*}$ - transition from blue $\left(-b^{*}\right)$ to yellow $\left(+b^{*}\right)$.

\section{Physical characteristics of the powders}

The solubility was determined according to the method described by Cano-Chauca et al. (2005), which consists of adding $0.5 \mathrm{~g}$ of the powder to $50 \mathrm{~mL}$ of distilled water on the magnetic stirrer at $1000 \mathrm{rpm}$ for $5 \mathrm{~min}$. Then the samples were subjected to centrifugation at $2600 \mathrm{rpm}$ for $5 \mathrm{~min}$. An aliquot of $12.5 \mathrm{~mL}$ of precipitate was taken to the oven at $105{ }^{\circ} \mathrm{C}$ for $24 \mathrm{~h}$ and the solubility was calculated by the weight difference, in which the solubility in \% is equal to the mass of the precipitate powder divided by the mass of total powder, the value is then multiplied by 100 .

The hygroscopicity was determined according to the methodology proposed by Cai and Corke (2000), in which samples of approximately $1 \mathrm{~g}$ of each powder were placed in Petri dishes, inside airtight containers containing saturated solution of $\mathrm{NaCl}$ (relative humidity $\approx 75.29 \%$ at $25^{\circ} \mathrm{C}$ ), at a controlled temperature of $25^{\circ} \mathrm{C}$ for a period of 8 days. After this period, the hygroscopic moisture was weighted and expressed in $\mathrm{g}$ of moisture per $100 \mathrm{~g}$ of dry solids (g/100 g).

The bulk density ( $\rho a p)$ was determined with the aid of a 10 $\mathrm{mL}$ test tube previously weighted and subsequently filled with the powder; the density was determined by the ratio 
mass/volume. The tapped density ( $\rho c)$ was determined with the material used in the bulk density by subjecting the test tube filled with the sample to tap for 50 times over the bench top, from a predetermined height of $2.5 \mathrm{~cm}$, the ratio mass/ tapped volume was calculated according to the methodology described by Tonon et al. (2009).

The Carr index $(\mathrm{Cl})$, which corresponds to the flowability index and the Hausner ratio (HR), which evaluates the cohesiveness of the powder were determined by the methodology of Wells (1988) and calculated from the data of bulk ( $\rho a p)$ and tapped density ( $\rho c)$.

The data of the analyses were submitted to analysis of variance and the means were compared by the Tukey test at $5 \%$ probability using the Sisvar software version 5.6 (Ferreira, 2014).

\section{Thermal degradation of the lyophilized hibiscus}

The thermal degradation was performed by diluting the samples powder in distilled water in the ratio of 1:10, then they were heated in water bath at the temperatures of 30 , $40,50,60$ and $70^{\circ} \mathrm{C}$ for a period of 10 minutes; the analysis of the bioactive compounds of flavonoids and anthocyanins were carried out according to the method described by Francis (1982), in which $0.2 \mathrm{~g}$ of the sample was diluted in 40 $\mathrm{mL}$ of the extractive solution of $\mathrm{HCl}$ ethanol $(1.5 \mathrm{~N})$ in the ratio 85:15, kept in a dark environment and resting for $24 \mathrm{~h}$ under refrigeration. The readings were performed in spectrophotometer at a wavelength defined at 374 and 535 $\mathrm{nm}$ of absorbance for flavonoids and anthocyanins respectively. The color appearance parameters were already mentioned above, and the values of $\mathrm{a}^{*}$ and $\mathrm{b}^{*}$ were used to calculate the values of chroma $\left(\mathrm{C}^{*}\right)$ and hue angle $(\mathrm{h})$.

\section{Statistical analysis}

The data of chemical, physical and physicochemical characterizations were submitted to analysis of variance in triplicate with the means compared by the Tukey test at $5 \%$ probability.

The data obtained in the kinetics of thermal degradation of freeze-dried powders were applied to a completely randomized design in a $4 \times 5$ factorial scheme: four powders with different proportions of maltodextrin $(0,5,10$ and $15 \%)$ and five temperatures $\left(30,40,50,60\right.$ and $\left.70^{\circ} \mathrm{C}\right)$. The analyzes were performed in triplicate and the Tukey test was used to compare the means.

In both materials, the Sisvar software version 5.6 was used (Ferreira, 2014).

\section{Conclusion}

It was observed that with the increase in maltodextrin proportion, the powders of the freeze-dried hibiscus extract presented increase in solubility, $\mathrm{pH}$ and total soluble solids, as well as decrease in hygroscopicity, water content, ash and acidity; all the powders presented good flowability and low to medium cohesion. The powders with higher concentrations of maltodextrin presented higher lightness and better preservation of red and yellow intensity. The maltodextrin is efficient in the preservation of anthocyanins of the freeze-dried hibiscus flower up to the temperature of $50{ }^{\circ} \mathrm{C}$ and the heating of the extracts powder significantly changed the hue and intensity of color under the evaluated conditions, due to the exponential degradation of the anthocyanins and flavonoids present in the extracts throughout the heating; Thus, this work resulted in the preparation of a product derived from the freeze-drying process with and without additives and with preserved sensory attributes of high quality.

\section{References}

Alves CCO, Resende JV, Cruvinel RSR, Prado MET (2008) Estabilidade da microestrutura e do teor de carotenóides de pós obtidos da polpa de pequi (Caryocar brasiliense Camb.) liofilizada. Ciênc Tecnol Aliment. 28(4):830-839.

Arancibia-avila P, Namiesnik J, Toledo F, Werner E, Martinezayala AL, Rocha-guzmán NE, Gallegos-infante A, Gorinstein S. (2012) The influence of different time durations of thermal processing on berries quality. Food Control. 26:587-593.

Brito ACW, Junior BD, Stertz SC, Freitas RJS (2011) Caracterização e estabilidade de purê misto de frutas, fonte de fibra alimentar. B Ceppa. 29 (1): 137-146.

Cai YZ, Corke H (2000) Production and properties of spraydried Amaranthus betacyanin pigments. J Food Sci. 65(6):1248-1252.

Caliskan G, Dirim NS (2016) The effect of different drying processes and the amounts of maltodextrin addition on the powder properties of sumac extract powders. Powder Technol. 287(1):308-314.

Cano-chauca M, Stringheta PC, Ramos AM, Cal-vidal J (2005) Effect of the carriers on the microstructure of mango powder obtained by spray drying and its functional characterization. Innov Food Sci Emerg Technol. 5(4):420428.

Canuto GAB, Xavier AAO, Neves LC, Benassi MT (2010) Caracterização físico-química de polpas de frutos da amazônia e sua correlação com a atividade anti-radical livre. Rev Bras Frutic Jaboticabal. 32(4):1196-1205.

Cavalcante Neto AA. (2017) Desidratação de cuxá em leito de espuma: avaliação da cinética de secagem e da qualidade do produto em pó. $116 \mathrm{f}$. Tese (Doutorado em Tecnologia de alimentos) - Universidade Estadual Paulista "Júlio de Mesquita Filho", São José do Rio Preto.

Costa JP, Rocha EMFF, Costa JMC (2014) Study of the physicochemical characteristics of soursop powder obtained by spray drying. Food Sci Technol. 34(4):663-666.

Fernandes RVB, Queiroz F, Botrel DA, Rocha VV, Souza VR, Lima CF (2014) Estudo da adição de albumina e da temperatura de secagem nas características de polpa de tomate em pó. Semina: Ciênc Agrár. 35(3):1267-1278.

Ferreira DF (2014) Sisvar: a Guide for its Bootstrap procedures in multiple comparisons. Ciênc Agrotec. 38(2):109-112.

Francis FJ (1982) Analysis of anthocyanins. In: Markakis, P. (ed.) Anthocyanins as food colors. New York: Academic Press. 181-207.

Galmarini MV, Baren C, Zamora MC, Chirife J, Lira PDL, Bandoni A (2011) Impact of trehalose, sucrose and/or maltodextrin addition on aroma retention in freeze dried strawberry puree. Intern. J of Food Scien. Technol. Oxford. 46(7): 1337-1345.

Hayashi, K. (1962). Chemistry of Flavonoid Compounds (ed. TA Geissman): 248-285. Pergamon Press, Oxford.

Instituto Adolfo Lutz. Métodos físico-químicos para análise de alimentos. 4. ed. São Paulo: Inst. Adolfo Lutz, 2008.

Maciel MJ, Paim MP, Carvalho HHC, Wiest JM (2012) Avaliação do extrato alcoólico de hibisco (Hibiscus sabdariffa L.) como fator de proteção antibacteriana e antioxidante. Rev Inst Adolfo Lutz. 71(3):462-470. 
Manzocco L, Calligaris S, Mastrocola D, Nicoli MC, Lerici CR (2000) Review of non-enzymatic browning and antioxidant capacity in processed foods. Trends Food Sci Tech. 11:340346.

Martins LM, Carlos LA, Gonçalves AA, Oliveira KG, Paiva CL (2018) Tratamento térmico no teor de antocianinas e características sensoriais de bebida não alcoólica de vinagreira. Perspect. Online: Biol. Saúde. 8(27):27-37.

Medeiros ML, Lannes SCS (2010) Propriedades físicas de substitutos do cacau. Ciênc Tecnol Aliment. 30(1):243-253.

Mosquera LH, Moraga G, Navarrete NM (2012) Critical water activity and critical water content of freeze-dried strawberry powder as affected by maltodextrin and arabic gum. Food Res Int Kidlington. 47(2):201-206.

Oliveira GS, Costa JMC, Afonso MRA (2014) Caracterização e comportamento higroscópico do pó da polpa de cajá liofilizada. Rev. Bras. Eng. Agríc. Ambient. 18 (10):1059-1064.

Oliveira MN, Figueirêdo RMF, Queiroz AJM, Diogenes AMG, Sousa ABB, Vasconcelos UAA (2017) Caracterização físicoquímica de polpas de manga 'Rosa' liofilizadas. Rev. Verde Agroecologia Desenvolv. Sustent. 2(5):902-906.

Rhim JW, Koh S, Kim JM (2011) Effect of freezing temperature on rehydration and water vapor adsorption characteristics of freeze-dried rice porridge. J Food Eng. 104 (4):484-491.

Santhalakshmy S, Bosco SJD, Francis S, Sabeena M (2015) Effect of inlet temperature on physicochemical properties of spray-dried jamun fruit juice powder. Powder Technol. 274 (1):37-43.

Sharma A, Jana AH, Chavan RS (2012) Functionality of milk powders and milk-based powders for end use applicationsd: A review. Compr Re. Food Sci F. 11 (5):518-528.

Silva AB, Wiest JM, Carvalho HHC (2016) Compostos químicos e atividade antioxidante analisados em Hibiscus rosa-sinensis L. (mimo-de-vênus) e Hibiscus syriacus L. (hibisco-da-síria). Braz J Food Technol. 19:201-220.
Silva KC (2011) Importância dos alimentos funcionais e a introdução de ogms na dieta humana. In: Simpósio de Ensino e Graduação, 9, Anais UNIMEP.

Silva RA, Petter CO, Schneider IAH (2007) Avaliação da perda da coloração artificial de agatas. REM: R.Esc.Minas. 60(3):477-482.

Sobota JF, Pinho MG, Oliveira VB (2016) Perfil físico-químico e atividade antioxidante do cálice da espécie Hibiscus sabdariffa L. a partir do extrato aquoso e alcoólico obtidos por infusão e decocto. Rev Fitos. 10(1):33-46.

Sogi DS, Siddiq M, Dolan KD (2015) Total phenolics, carotenoids and antioxidant properties of Tommy Atkin mango cubes as affected by drying techniques. LWT - Food Sci Technol. 62(1):564-568.

Souza AV, Vieites RL, Gomes EP, Vieira MRS (2018) Biochemical characterization of blackberry fruit (Rubus sp) and jellies. Aust J Crop Sci. 12:624-630.

Timberlake CF, Bridle P. (1975). Anthocyanins, in The Flavonoids (Eds: Harbone JB, Mabry TJ, Mabry H.). Springer, Boston, MA.

Tonon RV, Brabet C, Hubinger MD (2009) Influência da temperatura do ar de secagem e da concentração de agente carreador sobre as propriedades físico-químicas do suco de açaí em pó. Ciênc Tecnol Aliment. 29:444-450.

Yusof YA, Salleh FSM, Chin NL, Talib RA (2012) The drying and tabletting of pitaya powder. J. Food Process Eng. 35(5):763771.

Zotarelli MF, Porciuncula BDA, Laurindo JBA (2012) convective multi-flash drying process for producing dehydrated crispy fruits. J Food Eng. 108 (4):523-531.

Wells JI (1988) Pharmaceutical Preformulation: The Physicochemical Properties of Drug Substances. New York: John Wiley \& Sons. 